\title{
Circulating miRNA Expression in Asthmatics is Age- related and Associated with Clinical Asthma Parameters, Respiratory Function and Systemic Inflammation
}

\author{
Aleksandra Wardzyńska ( $\nabla$ aleksandra.wardzynska@umed.lodz.pl) \\ Pawełczyk Małgorzata \\ Medical University of Lodz: Uniwersytet Medyczny w Lodzi \\ Joanna Rywaniak \\ University of Lodz \\ Joanna Samanta Makowska \\ Medical University of Lodz: Uniwersytet Medyczny w Lodzi \\ Joanna Jamroz- Brzeska \\ Medical University of Lodz: Uniwersytet Medyczny w Lodzi \\ Marek Leszek Kowalski \\ Medical University of Lodz
}

Medical University of Lodz: Uniwersytet Medyczny w Lodzi https://orcid.org/0000-0001-6253-2799

\section{Research}

Keywords: asthma, innate immunity, basic immunology, elderly, miRNA, systemic inflammation

Posted Date: December 11th, 2020

DOl: https://doi.org/10.21203/rs.3.rs-124946/v1

License: (c) (i) This work is licensed under a Creative Commons Attribution 4.0 International License.

Read Full License 


\section{Abstract}

Background: Asthma in elderly asthmatics (EA) may have a different course than in non-elderly asthmatics (nEA), which may be partially associated with age-dependent aberrant immune response. The aim of the study was to assess the association of serum miRNA expression with asthma characteristics and systemic inflammation markers in EA and nEA.

Methods: In 28 EA and 31 nEA patients, control and severity of asthma, pulmonary function and FeNO were assessed. The control group included 59 age-matched non-asthmatics. Expression of selected miRNAs in serum was measured with RT-PCR, and proinflammatory cytokines were assayed by ELISA or flow cytometry.

Results: EA had lower serum expression of miRNA -19b and -146a, while the $\mathrm{nEA}$ had a higher expression of miRNA -146a than controls. EA had a higher serum expression of miRNA -106a and -126a than nEA. In all asthmatics, miRNA -106a and -126a were correlated with age. Only in nEA, the expression of selected miRNAs was associated with the level of asthma control (assessed with ACT) and with airway inflammation, measured by FeNO concentration. Elevated levels of systemic inflammation markers were associated with impaired respiratory function in all asthmatics and with worsened asthma control in the elderly patients. A significant correlation was observed between serum levels of proinflammatory cytokines and selected miRNAs.

Conclusion: Serum miRNA expression was correlated with clinical characteristics of asthma and systemic inflammation in an age-dependent fashion suggesting that miRNA may differentially contribute to asthma pathogenesis in elderly and non-elderly patients.

\section{Introduction}

Asthma in the elderly may be a challenging problem for a clinician since elderly patients represent almost all known phenotypes of asthma which are further modified by physiological ageing and presence of comorbidities, . Age-related changes in the respiratory system which include diminished muscle strength, lung compliance and decreased lung function, may influence the manifestation and severity of asthma symptoms in the elderly. An important factor that can affect asthma is progressive impairment of the immune response with age referred to as 'Immunosenecence'. It seems to be associated with an elevated level of proinflammatory cytokines, referred to as systemic inflammation (SI), which may originate from non-specific activation of innate cells, oxidative stress or persistent viral infections, . The increased level of proinflammatory cytokines can be a risk factor for mortality in the elderly population and is found in several inflammatory disorders including Alzheimer disease, diabetes mellitus, as well as in chronic pulmonary obstructive disorders such as COPD and asthma, , .

MicroRNAs are short (18-22 nucleotides), noncoding RNA molecules, that bind to target sequences in mRNA and cause post-translational changes at the epigenetic level. MicroRNAs can regulate the expression of more than half of mammalian genes and are involved in controlling of several 
physiological processes including ageing. Dysregulation of miRNAs has also been implicated in the pathophysiology of bronchial asthma ${ }^{12}$. However, the potential role of the serum miRNAs as a biomarker of disease activity and control has not been fully elucidated, , .

In this study, we aimed to assess the relationship between the expression of selected miRNA in the serum, clinical parameters and systemic inflammation markers in elderly and non-elderly patients with asthma.

\section{Material And Methods}

\section{Patients and study outline}

The study included 59 patients with asthma diagnosed according to the Global Initiative for Asthma (GINA) 2016 criteria and 59 age - matched control subjects without respiratory disorders. The study subjects were divided into elderly (31 asthmatics and 29 controls aged over 65 years) and non-elderly (29 patients asthmatics and 29 controls aged 30-50) groups. At one appointment, spirometry, impulse oscillometry (IOS), FeNO (Fractional exhaled Nitric Oxide) measurement, and skin prick tests (SPTs) with a panel of inhalant allergens were performed and a blood sample was collected. The Asthma Control Test (ACT) and mMRC (modified Medical Research Council) scores were recorded and an extended questionnaire, including history of exacerbation, presence of comorbidities and infection, was filled in.

Characteristics of asthmatics and controls are presented in Table 1. 
Table 1

Detailed clinical characteristics of the study groups.

\begin{tabular}{|llll|}
\hline & asthma, $\mathbf{n = 5 9}$ & control, $\mathbf{n = 5 9}$ & $\mathbf{p}$ \\
\hline women, $\mathrm{n} / \mathrm{N}(\%)$ & $36 / 59(61 \%)$ & $41 / 59(69.5 \%)$ & $\mathrm{ns}$ \\
\hline age $y r s$, mean $\pm \mathrm{SD}$ & $54.5 \pm 16.8$ & $52.8 \pm 18.3$ & $\mathrm{~ns}$ \\
\hline current smokers, n/N (\%) & $4 / 59(6.8 \%)$ & $7 / 59(11.9 \%)$ & $\mathrm{ns}$ \\
\hline atopy, n/N (\%) & $35 / 59(59.3 \%)$ & $24 / 59(40.7 \%)$ & 0.006 \\
\hline BMI, mean \pm SD & $27.82 \pm 5.7$ & $25.6 \pm 4.03$ & 0.02 \\
\hline BMI > 25, n/N (\%) & $40 / 59(67.8 \%)$ & $27 / 59(45.8 \%)$ & 0.01 \\
\hline FEV1\%pred. val., mean \pm SD & $91.8 \pm 18.2$ & $106.7 \pm 16.2$ & $<0.001$ \\
\hline MEF75/25\%pred. val., mean \pm SD & $51.6 \pm 24.7$ & $77.2 \pm 28.4$ & $<0.001$ \\
\hline FEV1\%/FVC, mean \pm SD & $69.6 \pm 9.3$ & $77.2 \pm 8.8$ & $=0.001$ \\
\hline R5Hz \%pred. value, mean \pm SD & $133.6 \pm 49.3$ & $97.7 \pm 23.4$ & $<0.001$ \\
\hline abnormal X5 Hz, n/N (\%) & $16 / 58(27.6 \%)$ & $5 / 58(8.6 \%)$ & 0.007 \\
\hline SR5-R20\% pred., mean \pm SD & $28.5 \pm 21.4$ & $17.3 \pm 13.4$ & 0.006 \\
\hline SR5-R20 > 20\%, n/N (\%) & $36 / 58(62.1 \%)$ & $19 / 58(32.8 \%)$ & 0.001 \\
\hline SAO, n/N (\%) & $11 / 58(19 \%)$ & $0 / 58(0 \%)$ & $<0.001$ \\
\hline FeNO ppb, mean \pm SD & $28.3 \pm 23.4$ & $21.8 \pm 8.3$ & $n s$ \\
\hline
\end{tabular}

The study was approved by the Bioethical Committee at the Medical University of Lodz (approval no. RNN/166/14/14/KE). All the study subjects provided their informed consent.

\section{Skin prick tests}

The panel of SPTs (Allergopharma, Reinbek, Germany) included the following inhalant allergens:

Dermatophagoides pteronyssinus, Dermatophagoides farinae, cat, dog, tree mix, grass mix, weed mix, Alternaria tenuis, and Cladosporium herbarum. A wheal of $3 \mathrm{~mm}$ in diameter was regarded as a positive result. Atopy was diagnosed in the event of at least one positive skin test.

\section{Assessment of respiratory function}

Spirometry was performed according to the ERS standards[18], using the Vyntus system spirometer (Carefusion, San Diego, California, the United States). Impulse oscillometry (IOS) measurement was performed in triplicate, using the impulse oscillometer Vyntus System (Carefusion, San Diego, California, 
the United States). When taking the measurements, patients were seated, breathed through a mouthpiece, with a nose clip and their cheeks and mouth supported.

Respiratory muscle strength was assessed by measuring maximal inspiratory and expiratory pressure (MIP and MEP) using the Vyntus System (Carefusion, San Diego, California, United States).

\section{FeNO measurement}

The patients performed single breath maneuvers online according to the ATS/ERS guidelines[19], using the HypAir FeNO (Medisoft, Belgium). The mean value of at least two successful measurements was analyzed. FeNO measurement was performed before spirometry and IOS.

\section{Serum miRNA assessment}

The miRNA was isolated from the serum with miRCURY RNA Isolation Kit-Biofluids (Exiqon, Vedbaek, Denmark) according to the manufacturer's protocol. Equal volumes of RNA were used to prepare complementary DNA (cDNA) with the universal cDNA Synthesis Kit (Exiqon). They were used to perform quantitative PCR (StepOne Plus; Applied Biosystems, Foster City, CA, US) with miR-93 as a reference gene. Serum expression levels were evaluated for miR-106a-5p, miR-146a-5p, miR-19b-3p, miR-126a-5p with real-time PCR. The microRNAs were chosen based on the results of serum miRNA profiling performed in the same population and validation study (data not published).

\section{Measurement of serum cytokines}

The serum levels of TNF- $\alpha$, IL- $1 \beta$ and IL- 6 were determined with the use of the commercial Thermo Fisher Scientific Ultrasensitive TNF alpha Human ELISA Kit, High Sensitivity IL-1 beta Human ELISA Kit and High Sensitivity IL-6 Human ELISA Kit. Serum level of soluble TNF RI was determined with the use of the commercial R\&D Systems Human TNF RI/TNFRSF1A Quantikine ${ }^{\circledR}$ ELISA Kit. IL-12p70, IL-10 and IL-8 levels in the serum were measured with the $\mathrm{BD}^{\mathrm{T}}$ Cytometric Bead Array Human Inflammatory Cytokine Kit. The samples were run on a $\mathrm{BD}^{\mathrm{Tm}} \mathrm{LSR}$ Fortessa flow cytometer and the results were analyzed with the BD $^{\mathrm{TM}}$ FCAP Array software.

IL-10 was detectable only in 48/119 (40.3\%), IL12p70 in 20/119 (16.8\%) and IL $1 \beta$ in 10/119 (8.4\%) of the study participants, and these cytokines were not included in the analysis.

\section{Statistical analysis}

Comparisons between the groups were made with the non-parametric Mann-Whitney $\mathrm{U}$ test. The Spearman rank correlation was used to evaluate a correlation between the variables. The statistical 
analysis was performed using Statistica 13.1 (TIBCO Software Inc., USA). P values $<0.05$ were accepted as statistically significant.

\section{Results}

\section{Clinical characteristic of patients}

The characteristic of the elderly (EA) and non-elderly asthmatics (nEA) is presented in the Table 2. EA showed a more severe airway obstruction both in the large airways (as assessed by spirometry) and in the small airways (as assessed by IOS). Both groups demonstrated a similar level of asthma control and comparable severity according to the GINA criteria. However, EA more frequently reported exacerbation in the last 12 months and received a higher mMRC score. 
Table 2

Comparison between elderly and non-elderly asthmatic patients.

\begin{tabular}{|c|c|c|c|}
\hline & $\begin{array}{l}\text { elderly asthma, } n= \\
28\end{array}$ & $\begin{array}{l}\text { non-elderly asthma, } \mathrm{n}= \\
31\end{array}$ & $\mathbf{p}$ \\
\hline women, n/N (\%) & $17 / 28(60.71 \%)$ & $19 / 31(61.29 \%)$ & ns \\
\hline age yrs, mean $\pm S D$ & $71 \pm 5.4$ & $39.5 \pm 5.8$ & $\begin{array}{l}<.001 \\
0.001\end{array}$ \\
\hline age at asthma diagnosis, yrs, mean \pm SD & $52.3 \pm 15.9$ & $21.1 \pm 13.4$ & $\begin{array}{l}< \\
0.001\end{array}$ \\
\hline current smokers, n/N (\%) & $1 / 28(3.57 \%)$ & $3 / 31(9.68 \%)$ & ns \\
\hline atopy, n/N (\%) & $13 / 27(48.15 \%)$ & $22 / 25(88 \%)$ & 0.002 \\
\hline $\mathrm{BMI}$, mean $\pm \mathrm{SD}$ & $29.3 \pm 4.7$ & $26.5 \pm 6.3$ & 0.02 \\
\hline FEV1\%pred. val., mean \pm SD & $88.4 \pm 20.9$ & $94.8 \pm 15.1$ & ns \\
\hline FEV1\%/FVC, mean \pm SD & $64.5 \pm 8.9$ & $74.1 \pm 7.2$ & 0.001 \\
\hline MEF75/25\% pred. val., mean \pm SD & $36.6 \pm 17.9$ & $64.5 \pm 22.5$ & $\begin{array}{l}< \\
0.001\end{array}$ \\
\hline $\mathrm{R} 5 \mathrm{~Hz} \%$ pred. value, mean \pm SD & $142.6 \pm 59.5$ & $125.9 \pm 37.7$ & ns \\
\hline abnormal X5 Hz, n/N (\%) & $7 / 27(25.93 \%)$ & $9 / 31(29.03 \%)$ & ns \\
\hline$\delta R 5-R 20 \%$ pred., mean \pm SD & $35.2 \pm 22.2$ & $22.6 \pm 19.3$ & 0.02 \\
\hline SR5-R20 > 20\%, n/N (\%) & $20 / 27(74.07 \%)$ & $16 / 31(51.61 \%)$ & ns \\
\hline FeNO, ppb, mean \pm SD & $27.2 \pm 20.3$ & $29.2 \pm 25.9$ & ns \\
\hline \multicolumn{4}{|l|}{ Asthma control } \\
\hline $\mathrm{ACT}$, mean $\pm \mathrm{SD}$ & $19.5 \pm 5.8$ & $21.4 \pm 3.7$ & ns \\
\hline ACT < 20 score, $\mathrm{n} / \mathrm{N}(\%)$ & $11 / 27(40.74 \%)$ & 9/31 (29.03\%) & ns \\
\hline mMRC, mean \pm SD & $1.6 \pm 1.2$ & $0.9 \pm 1$ & 0.01 \\
\hline \multicolumn{4}{|l|}{ Asthma control according to GINA 2017} \\
\hline controlled, n/N (\%) & $10 / 27(37.04 \%)$ & $17 / 31(54.84 \%)$ & ns \\
\hline partially controlled, n/N (\%) & 9/27 (33.33\%) & $10 / 31(32.26 \%)$ & ns \\
\hline Uncontrolled, n/N (\%) & $8 / 27(29.63 \%)$ & $4 / 31(12.9 \%)$ & ns \\
\hline
\end{tabular}




\begin{tabular}{|lllc|}
\hline & elderly asthma, $\mathbf{n}=$ & $\begin{array}{l}\text { non-elderly asthma, } \mathbf{n}= \\
\mathbf{3 1}\end{array}$ & $\mathbf{p}$ \\
\hline Mild, $\mathrm{n} / \mathrm{N}(\%)$ & $6 / 28(21.43 \%)$ & $2 / 31(6.45 \%)$ & $\mathrm{ns}$ \\
\hline Moderate, $\mathrm{n} / \mathrm{N}(\%)$ & $6 / 28(21.43 \%)$ & $9 / 31(29.03 \%)$ & $\mathrm{ns}$ \\
\hline Severe, $\mathrm{n} / \mathrm{N}(\%)$ & $15 / 28(53.57 \%)$ & $16 / 31(51.61 \%)$ & $\mathrm{ns}$ \\
\hline Exacerbations in the last 12 months & & & \\
\hline $\begin{array}{l}\text { Patients with exacerbation/last year, } \mathrm{n} / \mathrm{N} \\
(\%)\end{array}$ & $19 / 28(67.9 \%)$ & $11 / 31(35.5 \%)$ & 0.012 \\
\hline Number of comorbidities, mean \pm SD & $6.68 \pm 2.57$ & $3.58 \pm 1.96$ & $<$ \\
\hline
\end{tabular}

\section{Circulating miRNA expression in non-elderly asthmatics correlated with asthma control and airway inflammation}

There was no difference in the serum miRNA expression between the asthmatics and non-asthmatics. However, when the age-stratified groups were compared, the EA subjects had lower expression of miRNA - 19b and miRNA-146a, while the nEA patients had a higher expression of miRNA - 146a than the agematched controls. The elderly asthmatics had a higher serum expression of miRNA - 106a and miRNA126a than nEA (Fig. 1). In all asthmatics, the serum miRNA - 106a and miRNA-126a expression levels were correlated with age $(r=0.29, p<0.0$ and $r=0.38, p<0.05$, respectively $)$. In EA, we found a positive correlation between the number of comorbidities and miRNA - 106 and $-126 a(r=0.42, p<0.0$ and $r=$ $0.6, p<0.05$, respectively) (Fig. 2).

Only in the non-elderly asthmatics, the expression of selected miRNAs was associated with the level of asthma control and airway inflammation. The patients with uncontrolled disease according to GINA demonstrated lower serum miRNA-106a and miRNA-126 expression ([Dct]: $-0.53 \pm 0.3 \mathrm{vs.} 0.06 \pm 0.42 ; p=$ 0.01 , and $-2.01 \pm 0.54$ vs. $-1.2 \pm 0.86 ; p=0.047$, respectively). Similarly, the patients with ACT $<19$ points had lower miRNA-126a and $-106 a$ expression ([Dct]: $-0.47 \pm 0.2$ vs. $0.17 \pm 0.38 ; p<0.001$ and $-2.08 \pm$ 0.52 vs. $-1.03 \pm 0.79 ; p=0.001$, respectively). The non-elderly asthmatics with a history of asthma exacerbation in the past 12 months had a significantly lower expression of miRNA-106a ([Dct]: $-0.19 \pm$ 0.53 vs. $0.08 \pm 0.37 ; p=0.04)$. ACT was positively correlated with miRNA-106a $(r=0.45, p<0.05)$ and with miRNA-126a $(r=0.44, p<0.05)$. The FeNO level in the non-elderly asthmatics was negatively correlated with miRNA-106a $(r=-062, p<0.05),-126 a(r=-0.6, p<0.05)$ and $-146 a(r=-0.41, p<0.05)$ (Fig. 3).

\section{Elevated levels of systemic inflammation markers were associated with worsened asthma control and the impaired}




\section{respiratory function as related to age}

In all asthmatics $(n=59)$, the mean TNFa and sTNF RI levels were elevated as compared to the control group (Fig. 4A). The sTNF RI level was correlated with the large airways (FEV1\% pred., FVC\%pred., PEF\%pred, FEV1\%FVC, R5Hz\% pred.) and the small airways (MEF75-25\%pred.; $\delta \mathrm{R} 5-20 \mathrm{~Hz}$ ) function (Table 3.) as well as positively correlated with mMRC $(r=0.56, p<0.05)$.

Table 3

Correlations between respiratory parameters assessed by spirometry and impulse oscillometry and selected serum cytokines concentrations in asthmatic patients $(n=59)$. For all $p$ $<0.05$

\begin{tabular}{|c|c|c|}
\hline & sTNF RI serum levels & IL-6 serum levels \\
\hline \multicolumn{3}{|c|}{ Spirometric parameters } \\
\hline FEV1\% pred. & -0.34 & -0.26 \\
\hline MEF75/25\% pred & -0.37 & ns \\
\hline FEV1\%/FVC & -0.31 & -0.28 \\
\hline \multicolumn{3}{|c|}{ Oscillometric parametrs } \\
\hline $\mathrm{R} 5 \mathrm{~Hz}$ & 0.43 & 0.33 \\
\hline fres & 0.44 & 0.32 \\
\hline$A X$ & 0.45 & 0.3 \\
\hline$\delta \mathrm{R} 5-\mathrm{R} 20 \mathrm{~Hz}$ & 0.4 & ns \\
\hline
\end{tabular}

In the EA group, serum levels of TNFa and sTNF RI were higher than in the nEA subjects, and higher as compared to age-matched controls (Fig. 4B.). In the elderly asthmatics, sTNF RI negatively correlated with ACT $(r=-0.5 ; p<0.05$, with the large airway function (FEV1\% pred. $(r=-0.49, p<0.05)$, and positively - with mMRC $(r=0.62, p<0.05)$. In the nEA participants, the sTNF RI level was positively correlated with R5 $\mathrm{Hz}$ $\%$ pred. $(r=0.4, p<0.05)$.

IL-6 serum levels in all asthmatic patients positively correlated with mMRC $(r=0.36, p<0.05)$ and were associated with a worse respiratory function assessed by both spirometry and IOS (Table 3). In the EA subjects, the IL- 6 serum level negatively correlated with ACT $(r=-0.42, p<0.05)$. In the nEA patients, IL-6 was positively correlated with mMRC $(r=0.43, p<0.05)$.

The serum level of IL-8 was significantly lower in the nEA participants than in the age-matched control group $(7.1 \pm 9.72 \mathrm{pg} / \mathrm{ml}$ vs. $8.9 \pm 6,57 \mathrm{pg} / \mathrm{ml} ; \mathrm{p}=0.047)$ and in the EA individuals, the serum level of IL-8 was negatively correlated with FEV1\%/FVC $(r=-0.62, p<0.05)$. 


\section{The level of proinflammatory cytokines was increased among asthmatics with small airway obstruction}

Some of the asthmatics demonstrated small airways obstruction (SAO) defined as presence of concurrently abnormal R5 Hz \%pred., X5 Hz and $\delta$ R5-R20 Hz.; the prevalence of SAO was similar in the EA and nEA groups (5/27 (18.52\% vs. $6 / 31$ (19.35\%), ns). SAO was not present in the healthy controls. Patients with SAO suffered from uncontrolled asthma more frequently (5/11 (45.5\%) vs. 6/47 (12.8\%), p $=0.02)$, had a higher number of frequent exacerbations (three and more) in the last 12 months $(6 / 11$ $(54.5 \%)$ vs. $5 / 47(10.6 \%), p=0.002)$, more often received extra courses of oCS in the last year $(6 / 11$ $(54.5 \%)$ vs $6 / 47(12.8 \%), p=0.004)$ and received a higher mMRC score $(1.91 \pm 1.22$ vs $1.02 \pm 1.06, p=$ 0.04). The level of proinflammatory cytokines was higher in the asthmatics with $S A O$ than in the patients without SAO - sTNF R $(1476.04 \pm 302.51 \mathrm{pg} / \mathrm{ml}$ vs.1231.42 $\pm 301.23 \mathrm{pg} / \mathrm{ml} ; \mathrm{p}=0.008)$ and IL-6 $(1.64 \pm$ $1.07 \mathrm{pg} / \mathrm{ml}$ vs. $1.2 \pm 0.9 \mathrm{pg} / \mathrm{ml} ; \mathrm{p}=0.02)$.

\section{Serum markers of systemic inflammation corelated with miRNA expression}

Serum sTNF RI levels in all the asthmatics correlated with miRNA-106a $(0.44, p<0.05)$ and miRNA -126a $(r=0.41, p<0.05)$, while in EA, miRNA -126a was positively correlated with TNF $a(r=0.5, p<0.05)$ and miRNA -146 a was negatively correlated with IL-8 $(r=-0.41, p<0.05)$. In the $n E A$ group, there was a positive correlation between the level of sTNF RI and miRNA -106a $(r=0.38, p<0.05),-126 a(r=0.37, p<0.05)$ and $-146 a(r=0.38, p<0.05)$.

\section{Discussion}

By basing on our previous miRNA profiling study, performed on PBMCs collected from elderly and nonelderly asthmatics and age-matched controls (unpublished), we have selected four miRNA potentially associated with asthma for further analyses. We found that only after stratification according to the age, differences in serum miRNA expression were observed between asthmatics and non-asthmatics. The elderly asthmatics had on average lower expression of microRNA - 19b and -146a than healthy subjects, while younger patients had higher miRNA - 146a serum levels than the age- matched controls. Aging is an important factor influencing expression of microRNAs and most studies report that miRNAs expression in serum or in PBMCs is downregulated in elderly subjects. Age-related changes in the expression of microRNAs were also associated with comorbidities, including coronary heart disease, hypertension, blood pressure and glucose levels. In our patients, the expression of miRNA- 126a and 106a was correlated with the total number of co-morbid diseases only in elderly asthmatics, confirming observations that other disorders with inflammatory background may also have an impact on age-related miRNA dysregulation. These observations suggest that age may modify expression of miRNAs to such extent that they cannot be serve as a reliable asthma biomarker in elderly individuals. 
In this study, the expression of miRNA-106a and - 126a was correlated with worsened asthma control and history of exacerbation only in younger asthmatics, whereas in the elderly, we did not find any associations between miRNAs and asthma traits. Other miRNAs were also reported to be differently expressed in severe asthmatics: including miRNA-221 assayed in airway smooth muscle cells from bronchial biopsies and miR-629-3p, miR-223-3p, and miR-142-3p in sputum cells. A few studies, mostly conducted on younger populations (children and younger asthmatics), revealed correlations between altered expression of selected microRNAs and spirometry parameters, . We have previously shown a correlation between serum miRNAs and respiratory function in a group of adults with moderate and severe asthma, but only during exacerbation, not on a follow up visit ${ }^{15}$.

As miRNAs are involved in regulation of inflammatory processes, we aimed to refer the serum miRNA expression to fractional exhaled NO, considered as a surrogate marker of bronchial eosinophilia and T2 type of inflammation. However, only in the non-elderly group, we found that expression levels of miRNA106a, -126a and - 146a were correlated with the FeNO level. Similarly, in a recent study by Weidner J et al., the expression of several circulating miRNAs, including miRNA-146a and -126 , was associated with blood eosinophilia and also with inhaled corticosteroid use. Neutrophilic asthma has also been correlated with a distinct miRNA profile in one study ${ }^{24}$ and a different group observed elevated expression of plasma miRNA-199a in asthmatics with an increased level of neutrophiles in induced sputum.

Several microRNAs have been studied in asthma and allergic disorders and most of them are involved in regulation of inflammatory processes, maintaining the epithelium homeostasis and in airways remodeling ${ }^{12}$. In our asthma patients, proinflammatory cytokines levels (TNFa and sTNF RI) were significantly elevated as compared to the healthy controls and were related to impaired respiratory function and clinical characteristics, including asthma control in both age groups. The role of systemic inflammation in the asthma pathogenesis has not been fully elucidated. Previously, serum levels of TNF receptors were found to be elevated during asthma attacks in atopic and non- atopic subjects. Recent observations of the two cohorts of asthmatics showed that the high IL- 6 level was associated with obesity and a more severe disease phenotype. In SARP cohorts, IL- 6 was associated with asthma severity and poor airway function and was also an indicator of non-type 2 asthma. The adipose tissue can be a major source of proinflammatory cytokines. Canoz et al. ${ }^{11}$ showed that ESR, CRP, TNF-a, IL-6, and leptin levels in obese asthma patients were higher than in healthy controls and TNF-a, IL-6, and leptin levels were higher in obese than in non-obese asthmatics. Our findings showed that BMI was not only related to worsened lung test results and elevated levels of SI cytokines (data not shown) but it was also significantly higher in elderly patients, which suggests that Inflammaging in obese asthmatics may be more pronounced.

In our study, the miRNA expression was correlated with proinflammatory cytokines level supporting the hypothesis that miRNA play a role in the regulation of systemic inflammation. A few studies documented that miRNAs are implicated in Th1 - Th2 polarization, regulation of T2 cytokine expression, , . In PBMCs isolated from asthmatic children, expression of miRNA-126a was associated with imbalance in IL-4/INF gamma production. In a study by Jardim et al. , 66 differently expressed microRNAs, mostly involved in 
regulating inflammatory pathway genes, were found in epithelial cells of asthmatics as compared to nonasthmatics. In our study, miRNA- 146a was negatively correlated with IL-8, which is induced by TNFa via NF-KB. miRNA-146a regulates NF- $\kappa$ B signaling pathway (by targeting directly the TNF receptor-associated factor 6 - TRAF6 and Interleukin-1 receptor-associated kinase 1- IRAK1). On the other hand, miRNAs can be induced by different proinflammatory stimuli, such as IL-1 $\beta$ and TNF.

Small airways dysfunction (SAO), which can be found in a subpopulation of asthma patients, has been associated with worsening of asthma control and greater severity of the disease in both children and adults. Our patients with SAO, regardless of age, were more frequently obese and were more prone to exacerbation. Similarly, in the recent study carried out on children, obesity was associated with both large and peripheral airway obstruction. Our patients with SAO had higher levels of IL- 6 and STNF RI suggesting that proinflammatory cytokines, may be involved in the pathogenesis of small airway obstruction.

To conclude, we observed that, depending on the age of asthmatic patients, expression of circulating miRNA may be differentially associated with asthma control and local airway and systemic inflammation.

\section{Abbreviations}

EA- elderly asthmatics, nEA- non-elderly asthmatics, SI- systemic inflammation, IOS- impulse oscillometry, FeNO-fractional exhaled Nitric Oxide, SPTs- skin prick tests, ACT- Asthma Control Test, mMRC- modified Medical Research Council, FEV1\% pred.- forced expiratory volume in one second \% of predicted value, FVC\%pred.- forced vital capacity \% of predicted value, PEF\%pred.- peak expiratory flow \% of predicted value, FEV1\%FVC- forced expiratory volume in one second/forced vital capacity ratio, MEF75-25\%pred.Maximal Expiratory Flow at $25-75 \%$ of the pulmonary volume $\%$ of predicted value, $\mathrm{R} 5 \mathrm{~Hz} \%$ pred.resistance at $5 \mathrm{~Hz}$, \% of predicted value, $\delta \mathrm{R} 5-20 \mathrm{~Hz}$ - difference of resistance at 5 and $20 \mathrm{~Hz}$, fres- resonant frequency, AX-rea of reactance, SAO- small airways obstruction, PBMCs- peripheral blood mononuclear cells, ESR- erythrocyte sedimentation rate, BMI- body mass index

\section{Declarations}

\section{Ethics approval and consent to participate}

The study was approved by the Bioethical Committee at the Medical University of Lodz (approval no. RNN/166/14/14/KE). All the study subjects provided their informed consent.

\section{Consent for publication}




\section{Availability of data and materials}

The data that support the findings of this study are available from the corresponding author upon reasonable request

\section{Competing interests}

The authors declare no conflict of interest.

\section{Funding}

This study was supported by the Polish National Science Centre grant no. UMO-2013/09/B/NZ6/00746.

\section{Authors' contributions}

AW, MLK and JSM designed the study. AW and MLK wrote this manuscript and analyzed the data. MP and JR performed the experiments. JJB participated in patients' recruitment. All authors read the manuscript and provided critical comments.

\section{Acknowledgements}

The authors would like to thank the nurses involved in the study, Mrs Teresa Niedzielska and Mrs Dorota Żaromińska, for their assistance.

\section{References}

1. Battaglia S, Benfante A, Spatafora M, Scichilone N. Asthma in the elderly: a different disease? Breathe. 2016;12:18-28.

2. Wardzyńska A, Kubsik B, Kowalski ML. Comorbidities in elderly patients with asthma: Association with control of the disease and concomitant treatment. Geriatr Gerontol Int. 2015;15:902-909.

3. Sharma G, Goodwin J. Effect of aging on respiratory system physiology and immunology. Clinical Interventions in Aging. 2006;1:253-260.

4. Busse PJ, Mathur SK. Age-related changes in immune function: effect on airway inflammation. $J$ Allergy Clin Immunol. 2010; 26:690-701. 
5. Goldstein DR. Aging, imbalanced inflammation and viral infection. Virulence. 2010;1:295-298.

6. Kowalski ML, Wardzynska A, Studzinska M, Pawełczyk M, Zbigniew Leśnikowski Z, Paradowska E. Cytomegalovirus DNA is highly prevalent in the blood of patients with asthma and is associated with age and asthma traits. Allergy. 2017;72:2035-2038.

7. Franceschi C, Campisi J. Chronic inflammation (inflammaging) and its potential contribution to ageassociated diseases. J Gerontol A Biol Sci Med Sci. 2014;69 Suppl 1:S4-S9.

8. Breyer M, Rutten E, Spruit M, Hop WCJ, Postma DS, Wouters EFM. Systemic Inflammation in Patients with Chronic Obstructive Pulmonary Disease: Results from the Cosmic Study. Open Journal of Respiratory Diseases. 2012; 2:63-72.

9. Yokoyama A, Kohno N, Fujino S, Hamada H, Inoue Y, Fujioka S, et al. Circulating interleukin-6 levels in patients with bronchial asthma. Am J Respir Crit Care Med. 1995;151:1354-8.

10. Neveu WA, Allard JL, Raymond DM, Bourassa LM, Burns SM, Bunn JY, et al. Elevation of IL-6 in the allergic asthmatic airway is independent of inflammation but associates with loss of central airway function. Respir Res. 2010;11:28.

11. Canöz M, Erdenen F, Uzun H, Müderrisoglu C, Aydin S. The relationship of inflammatory cytokines with asthma and obesity. Clin Invest Med. 2008;31:E373-E379.

12. Taka S, Tzani-Tzanopoulou P, Wanstall H Papadopoulos NG. MicroRNAs in Asthma and Respiratory Infections: Identifying Common Pathways. Allergy Asthma Immunol Res. 2020;12:4-23.

13. Kozomara A, Griffiths-Jones S. miRBase: annotating high confidence microRNAs using deep sequencing data. Nucleic Acids Res. 2014;42(Database issue):D68-D73.

14. Kinser HE, Pincus Z. MicroRNAs as modulators of longevity and the aging process. Hum Genet. 2020;139:291-308.

15. Wardzyńska A, Pawełczyk M, Rywaniak J, Kurowski M, Makowska JS, Kowalski ML. Circulating MicroRNAs and T-Cell Cytokine Expression Are Associated With the Characteristics of Asthma Exacerbation. Allergy Asthma Immunol Res. 2020;12:125-136.

16. Chen Y, Mao ZD, Shi YJ, Qian Y, Liu ZG, Yin XW, et al. Comprehensive analysis of miRNA-mRNAIncRNA networks in severe asthma. Epigenomics. 2019;11:115-131.

17. Rial MJ, Rodrigo Muñoz JM, Sastre B, Sastre J, Del Pozo V. Stability of Asthma Control Implies No Changes in microRNAs Expression. J Investig Allergol Clin Immunol. 2019;29:388-389.

18. Miller MR, Hankinson J, Brusasco V, Burgos F, Casaburi R, Coates A, et al. Standardisation of spirometry. Eur Respir J. 2005;26:319-38.

19. American Thoracic Society; European Respiratory Society. ATS/ERS recommendations for standardized procedures for the online and offline measurement of exhaled lower respiratory nitric oxide and nasal nitric oxide, 2005. Am J Respir Crit Care Med. 2005;171:912-30.

20. Zhang $\mathrm{H}$, Yang $\mathrm{H}$, Zhang $\mathrm{C}$, ing $\mathrm{Y}$, Wang $\mathrm{C}$, Liu $\mathrm{C}$ et al. Investigation of microRNA expression in human serum during the aging process. J Gerontol A Biol Sci Med Sci. 2015;70:102-9. 
21. Noren Hooten N, Abdelmohsen K, Gorospe M, Ejiogu N, Zonderman AB, Evans MK. microRNA expression patterns reveal differential expression of target genes with age. PLoS One. 2010;5:e10724.

22. Huan T, Chen G, Liu C, Bhattacharya A, Rong J, Chen BH et al. Age-associated microRNA expression in human peripheral blood is associated with all-cause mortality and age-related traits. Aging Cell. 2018;17:e12687.

23. Perry MM, Baker JE, Gibeon DS, Adcock IM, Chung KF. Airway smooth muscle hyperproliferation is regulated by microRNA-221 in severe asthma. Am J Respir Cell Mol Biol. 2014;50:7-17.

24. Maes T, Cobos FA, Schleich F, Sorbello V, Henket M, De Preter K, et al. Asthma inflammatory phenotypes show differential microRNA expression in sputum. J Allergy Clin Immunol. 2016;137:1433-46.

25. Kho AT, Sharma S, Davis JS, Spina J, Howard D, McEnroy K et al. Circulating MicroRNAs: Association with Lung Function in Asthma. PLoS One. 2016;11:e0157998.

26. Elbehidy RM, Youssef DM, El-Shal AS, Shalaby SM, Sherbiny HS, Sherief LM, et al. MicroRNA-21 as a novel biomarker in diagnosis and response to therapy in asthmatic children. Mol Immunol. 2016;71:107-114.

27. Weidner J, Ekerljung L, Malmhäll C, Miron N, Rådinger M. Circulating microRNAs correlate to clinical parameters in individuals with allergic and non-allergic asthma. Respir Res. 2020;7;21:107.

28. Huang Y, Zhang S, Fang X, Qin L, Fan Y, Ding D. et al. Plasma miR-199a-5p is increased in neutrophilic phenotype asthma patients and negatively correlated with pulmonary function. PLoS One. 2018;13:e0193502.

29. Virchow JC Jr, Kroegel C, Walker C, Matthys H. Inflammatory determinants of asthma severity: mediator and cellular changes in bronchoalveolar lavage fluid of patients with severe asthma. $J$ Allergy Clin Immunol. 1996;98:27-33.

30. Peters MC, McGrath KW, Hawkins GA, Hastie AT, Levy BD, Israel E. et al. Plasma interleukin-6 concentrations, metabolic dysfunction, and asthma severity: a cross-sectional analysis of two cohorts. Lancet Respir Med. 2016;4:574-584.

31. Li X, Hastie AT, Peters MC, Hawkins GA, Phipatanakul W, Li H et al. Investigation of the relationship between IL-6 and type 2 biomarkers in patients with severe asthma. J Allergy Clin Immunol. 2020;145:430-433.

32. Lu TX, Hartner J, Lim EJ, Fabry V, Mingler MK, Cole ET. et al. MicroRNA-21 limits in vivo immune response-mediated activation of the IL-12/IFN-gamma pathway, Th1 polarization, and the severity of delayed-type hypersensitivity. J Immunol. 2011;187:3362-3373.

33. Polikepahad S, Knight JM, Naghavi AO, Oplt T, Creighton CJ, Shaw C. et al. Proinflammatory role for let-7 microRNAS in experimental asthma. J Biol Chem. 2010;285:30139-30149.

34. Mattes J, Collison A, Plank M, Phipps S, Foster PS. Antagonism of microRNA-126 suppresses the effector function of TH2 cells and the development of allergic airways disease. Proc Natl Acad Sci $U$ S A. 2009;106:18704-18709. 
35. Malmhäll C, Alawieh S, Lu Y, Sjöstrand M, Bossios A, Eldh M. et al. MicroRNA-155 is essential for $\mathrm{T}(\mathrm{H}) 2$-mediated allergen-induced eosinophilic inflammation in the lung. J Allergy Clin Immunol. 2014;133:1429-1438.

36. Tian M, Ji Y, Wang T, Zhang W, Zhou Y, Cui Y. Changes in circulating microRNA-126 levels are associated with immune imbalance in children with acute asthma. Int J Immunopathol Pharmacol. 2018;32:2058738418779243.

37. Jardim MJ, Dailey L, Silbajoris R, Diaz-Sanchez D. Distinct microRNA expression in human airway cells of asthmatic donors identifies a novel asthma-associated gene. Am J Respir Cell Mol Biol. 2012;47:536-542.

38. Taganov KD, Boldin MP, Chang KJ, Baltimore D. NF-kappaB-dependent induction of microRNA miR146 , an inhibitor targeted to signaling proteins of innate immune responses. Proc Natl Acad Sci U S A. $2006 ; 103: 12481-12486$.

39. Sato T, Liu X, Nelson A, Nakanishi M, Kanaji N, Wang X, et al. Reduced miR-146a increases prostaglandin E囚in chronic obstructive pulmonary disease fibroblasts. Am J Respir Crit Care Med. 2010;182:1020-1029.

40. Bonini M, Usmani OS. The role of the small airways in the pathophysiology of asthma and chronic obstructive pulmonary disease. Ther Adv Respir Dis. 2015;9:281-93.

41. Ekström S, Hallberg J, Kull I, Protudjer JLP, Thunqvist P, Bottai M, et al. Body mass index status and peripheral airway obstruction in school-age children: a population-based cohort study. Thorax. 2018;73:538-545.

\section{Figures}



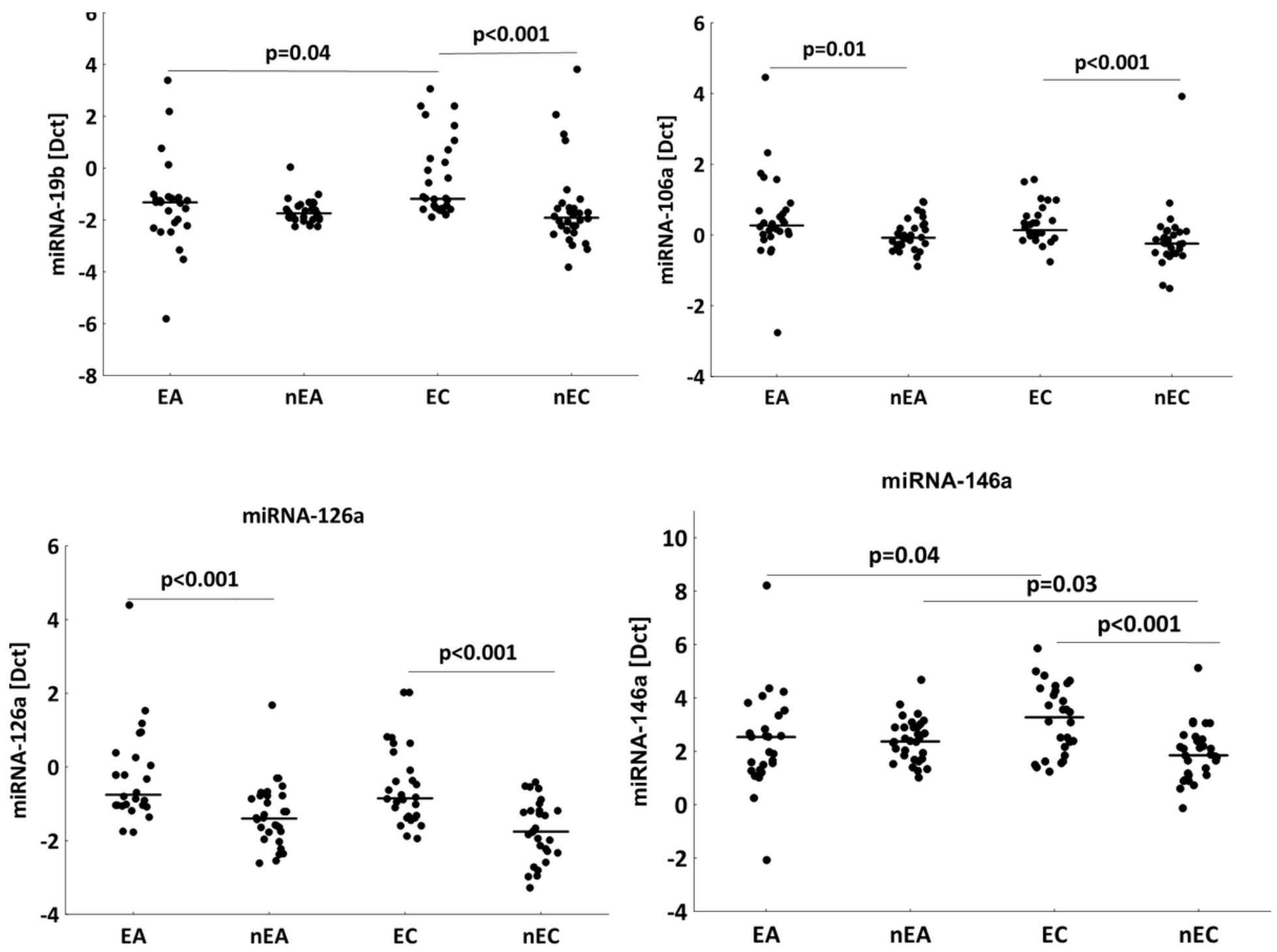

Figure 1

Expression of serum microRNA in the age-stratified groups of asthmatics and controls. The horizontal lines indicate median values. EA - elderly asthmatics, nEA - non-elderly asthmatics, EC - elderly controls, nEC - non-elderly controls. 

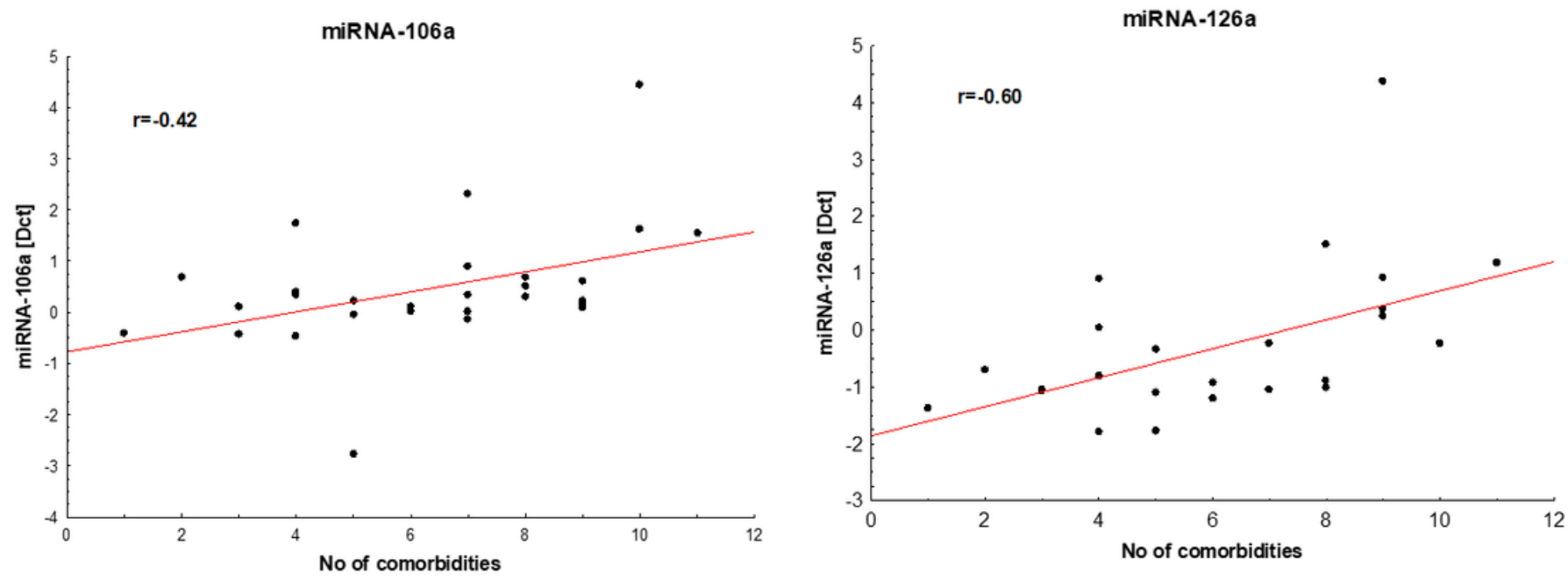

\section{Figure 2}

Correlations between the number of comorbidities and expression of miRNA-106a, -126a [Dct] in elderly asthmatics. For all $\mathrm{p}<0.05$.
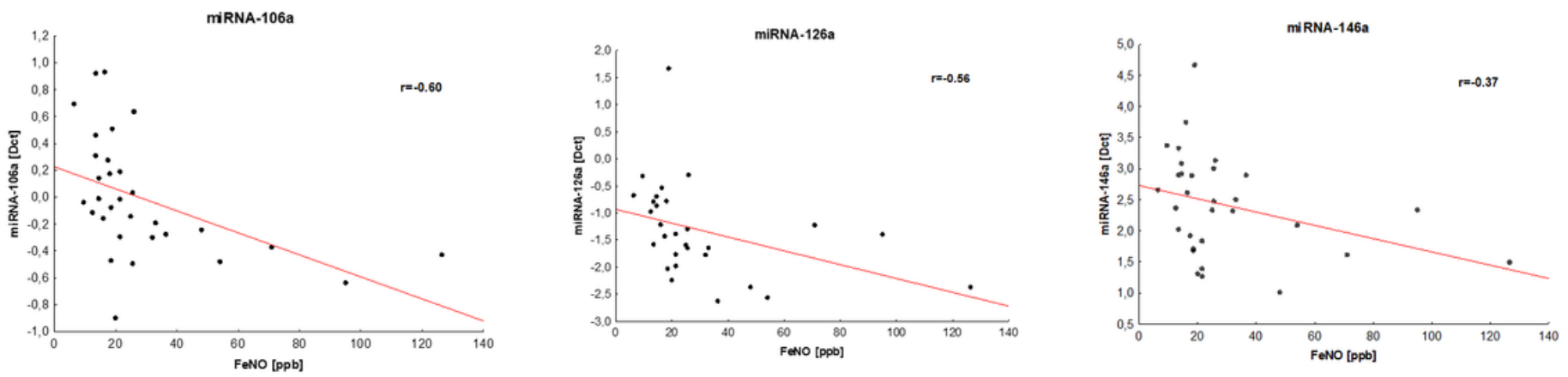

\section{Figure 3}

Correlations between FeNO [ppb] concentrations and serum expression of miRNA-146a, -126a and 106a [Dct] in non-elderly asthmatics. For all $p<0.05$. 

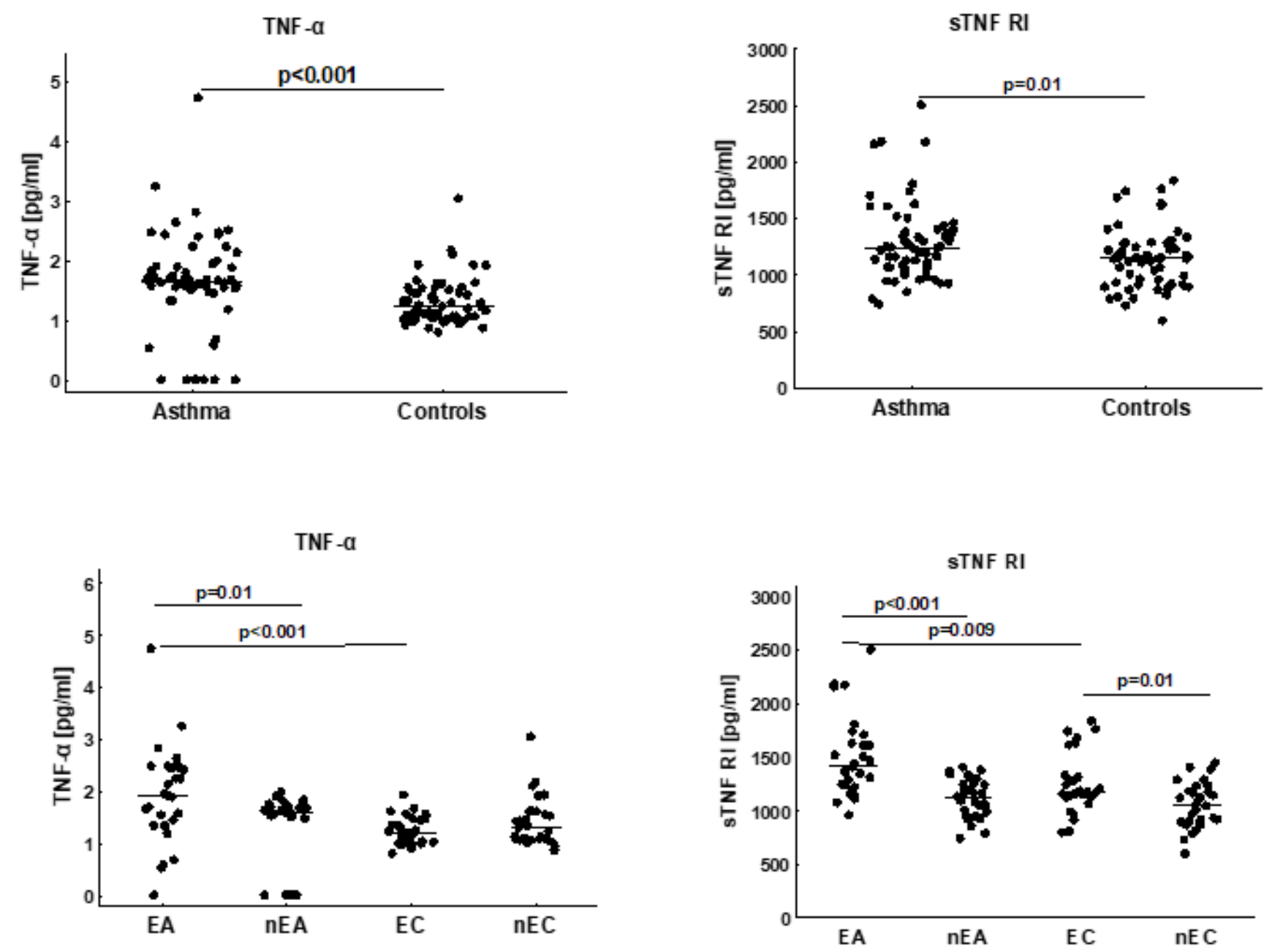

\section{Figure 4}

A. TNF $a$ and sTNF RI serum levels in the asthmatics and in the controls. B. TNF $a$ and sTNF RI serum levels in the age-stratified groups of asthmatics and controls. The horizontal lines indicate medians. EA elderly asthmatics, nEA - non-elderly asthmatics, EC - elderly controls, nEC - non-elderly controls. 